\title{
POESÍA CONTEMPORÁNEA EN LENGUA JUDEOES- PAÑOLA: MARGALIT MATITIAHU Y SU OBRA
}

\author{
Ana $\mathrm{M}^{\mathrm{a}}$ RIAÑO LÓPEZ, Universidad de Granada \\ $\mathrm{M}^{2}$ Carmen MARCOS CASQUERO, U.N.E.D., Guadalajara
}

\section{Introducción a la poesía contemporánea escrita en judeoespan̄ol}

Cuando hablamos de literatura sefardí contemporánea, hoy en avanzado proceso de extinción, nos estamos refiriendo sólo a un género, el de la poesía de autor, pues casi nada nuevo se ha compuesto en español sefardi en época cercana a nuestros dias que no sean poemas. Así, puede decirse que la literatura sefardí tiene en los poetas contemporáneos de lengua judeoespañola a sus más fervientes defensores, a sus olímpicos guardianes del fuego (léase "de la palabra') que, a golpes de súbitos fogonazos, mantienen encendidos los rescoldos de un pasado pleno en creatividad lingüística y literaria.

Conviene recordar que, en lo que concierne sólo a la poesía sefardí, de aquel pasado son el romancero y el cancionero, pertenecientes al género de la poesía tradicional de transmisión oral el cual, como era de esperar, se desarrolló en el exilio desde los comienzos de la literatura sefardí, siglo XVI, hasta el XX; y las coplas, poemas estróficos de autor, de transmisión libresca, género que se manifestó con extraordinaria madurez en el siglo XVIII. De modo que la poesía de autor es hija de la 'revolución' cultural, del cambio de mentalidad que se produjo en el seno de las comunidades sefardíes de la diáspora a mediados del siglo XIX, cuando el Imperio otomano se debilitaba y el gobiemo central no podía sofocar las aspiraciones nacionalistas de los diferentes pueblos, como el búlgaro, el griego o el armenio, que durante siglos habían vivido bajo su dominio. Esta situación de debilidad del Imperio propició la intervención cultural de Occidente, señaladamente de Francia, en aquellas tierras, en las que los sefardies, alentados por los principios de la Haskalá ('Ilustración') que en el siglo XVIll proclamó la necesidad de modernización de la literatura hebrea y de aceptación de los géneros literarios occidentales, tuvieron que padecer el menosprecio de la formación y de la creación al estilo tradicional y asumir las pautas 'a la francesa' prodigadas por toda la red de escuelas occidentalizantes que la Alliance Israélite Universelle había implantado en las áreas de asentamiento sefardíes. Surgió entonces una nueva forma de hacer literatura marcada por la moda del siglo, que minimizó los géneros tradicionales judios de corte fundamentalmente re- 
Ana M. "Riaño López y M. Marcos Casquèro

ligioso e introdujo los géneros seculares modernos desconocidos hasta entonces en el mundo sefardí: el periodismo, la novela, el teatro, el ensayo histórico. Junto a estos géneros y muchas veces dentro de ellos (tómese de ejemplo el periodismo, pues es en la prensa en donde hallamos no pocas publicaciones poéticas) creció y evolucionó la poesía de autor a través de los años, la cual completa la producción poética en judeoespañol.

Elena Romero' dedica un apartado al citado género, distribuyéndolo en textos para ser cantados y textos para la lectura. Dejamos el primer grupo, el
de "canzonetistas que compusieron textos poéticos destinados a reemplazar las letras de canciones en boga..." para otra ocasión, y del segundo recogemos que hubo un considerable nimero de poetas anteriores a la segunda gueтта mundial, que vivieron en la época de -todavía-casi plenitud precedente al imparable declive de la cultura sefardí, y que son los antecesores inmediatos de los autores que componen la última etapa del género, que es a la que se
refiere este artículo.

Aquellos autores siguieron el modelo de la poesía francesa, abandonando las formas estróficas judeoespañolas castizas por la utilización de tiradas de pareados formando falsas estrofas, estrofas de cuatro versos cortos monorrimos o aleluyas emparejadas y algunas de rima alterna en versos polimétriel caso de Selomó Sa, de Salónica, o El Juguetón, de Constantinopla. Tal es de poesías (Salónica, l901), autor de La gavilla (Salónica, 1900) y Cuaderno el citado periódico saloni), que contiene poemas que vieron la luz antes en la liberiad (Constantinoplase. Otras recopilaciones poéticas son Poesías de xiones (Esmirna, 1924) de 1908) de Semuel Mitrani, Impresiones y refle. Mosé David Gaon, Recolio de pquiyá Franco, Poesias (Jerusalén, 1925) de de poesias (Tel-Aviv, 1935), poesias diversas (Tel-Aviv, 1931) y Clradeno rida (Tel-Aviv, 1949) de Alexandro de Yishac A. de Botton, y Libertad que. cado, como acabamos de ver, no Pérez. Pues bien, a pesar de que lo publipues un abundante material, no fue mucho, menos aún es lo investigado, tiempo, al estudioso.

Desde finales de bros de poemas en los años sesenta en adelante, han visto la luz varios licitadas, ha prosperado la presemás de mantenerse las formas estróficas antes pues, la supervivencia de este género, verso libre. No deja de sorprendernos, un auge impensable desde la perspectiva de ua alcanzado en la actualidad cuya actividad en los demás géneros, ya de una literatura como la sefardí modernos, es, como dijimos antes, prą sean religiosos o patrimoniales, ya

\footnotetext{
' En La creación literaria en lengua sefardi, Madrid 1992, pp.212-217.
} 
Y puesto que de literatura hablamos será conveniente ofrecer, a modo de complemento, en esta introducción al género unas palabras acerca de la lengua en que fue y es escrita, a la vez que desechar algunos tópicos que desde el pasado siglo la acorralan. La lengua sefardí, judeoespañol o ladino, tiene su base en el habla de los siglos XV y XVI, un castellano semejante al expuesto en la Gramática de Antonio de Nebrija, bastante consolidado en sus características esenciales, aunque todavía con algunas vacilaciones que explicarian la presencia de arcaísmos - desde el punto de vista del español general- en la fonética, en la morfosintaxis y en el léxico. Algunos rasgos del sefardí, como la vacilación del timbre vocálico o la confusión $l$ y $r$, no son dialectales, sino vulgares y se hallan en todo el dominio hispánico en mayor o menor medida. Otros, como el seseo y el yeísmo, tampoco son exclusivos, aunque sí muy característicos del habla sefardí. Sus componentes procedían de distintas regiones españolas y proporcionaron al sefardi vocablos de sus regiones de origen. A los rasgos citados hay que sumar otros, los específicos producidos por la evolución experimentada durante los cinco siglos de su existencia como lengua 'viva', y, por último, los resultantes de su contacto con los numerosos y diversos países que acogieron a los sefardíes tras la expulsión de España decretada en 1492, es decir, aquellos elementos, especialmente léxicos, no hispánicos.

Durante los siglos XVI y XVII el judeoespañol fue exclusivamente lengua de traducción de la Biblia y de las literaturas rabínica y medieval escritas en hebreo. En el siglo XVIII alcanzó la madurez necesaria para ser además lengua propicia para la creación literaria y, en especial, poética, gracias a la fructífera actividad de los copleros, y en los siglos XIX y XX, el triunfo de la occidentalización y de la cultura francesa, al que nos hemos referido arriba, la nutrió de neologismos formados por derivación de palabras procedentes, en especial, del fruncés y del italiano, en un proceso semejante al que se produjo en el español del siglo XVIII y en el español de nuestros días. Así, en esta última etapa, nos hallamos ante un judeoespañol en el que la lengua tradicional y el pasado histórico, las vivencias y los recuerdos de otras épocas conviven con el hoy lingüístico (incorporación de palabras que no estaban en el vocabulario sefardí) y sentimientos provocados por nuevas situaciones y acontecimientos. Un judeoespañol no sólo mantenido sino enriquecido, cuyo rasgo más destacado es la rehispanización. Es este español sefardí el que conservan vivo los escasos sefardofonos que quedan en el mundo y de entre ellos los poetas de hoy.

En la investigación que hemos realizado hasta ahora hemos recurrido fundamentalmente a la lectura y análisis (pues poquísimos estudios existen) de las principales obras de aquellos autores que por sus aportaciones al género y por su reconocida trayectoria literaria, que abarca desde comienzos de este siglo hasta nuestros días, representan con merecimiento a la poesía con- 
Ana M. ${ }^{a}$ Riaño López y M. "Marcos Casquero

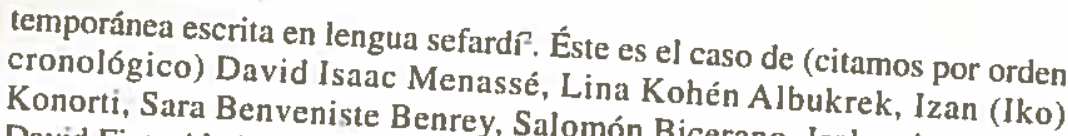
David Fintz Altabé, Margalit Matitialomón Bicerano, Isahar Avzaradel, Clarisse Nicoïdski-Abinun, Matilda Kita Gabbaï-Simantov, Sara Yohay, geográficamente abarcan desde Turquén-Sarano y Avner Pérez, los cuales Italia, Francia, Estados Unidos o Turquía, Grecia, Bulgaria o Israel hasta dos' cuya lengua es perviver o incluso España. Los hay 'Ios más allegadasición del mundo sefardí; y los de lo que era la lengua antes de la descompode la 'nueva' de la actual etapa.

Los temas que aparecen en las obras de estos autores son muy variados.

Podemos clasificarlos en dos grandes grupos: los que abarcan temas universales, comunes en la producción poética de cualquier Jiteratura occidental u oriental, y los específicamente judíos, que, evidentemente, engloban temas sefardíes. Entre los del primer grupo destacan la separación y ausencia del amado o de Jos hijos, la añoranza del hogar, de la patria lejana, de la familia, la muerte de algün familiar, de un hermano, de la madre, la pérdida de un amigo. Pero también el amor, la llegada del amado, Ja alegría del regreso, el reencuentro de madres e hijos tras la sepuración de la guerra. Hay poemas en los que se dan consejos sobre la vida, los sentimientos, la conciencia, la paciencia, el mal obrar; más los que ponen de manifiesto preocupaciones existenciales (de dónde venimos, quiénes somos...), o tratan del amor propio en el amor. No faltan las disquisiciones sobre la fama, que cuando se pierde no vuelve a recuperarse, ni los versos que cantan a la pobreza o que aluden al sufrimiento, a la soledad, a la fortaleza, a la dulzura; otros se refieren al paso del tiempo, a las etapas de la vida: la juventud, la vejez. Los hay que son exaltación de la escuela, de la libertad, evocación del mar, de la patria, de la cast, y algunos muy curiosos dedicados a las reflexiones de una rosa, a una gallina, a la cocinera, a la comida y el guisado y hasta al ladrón. También ha-

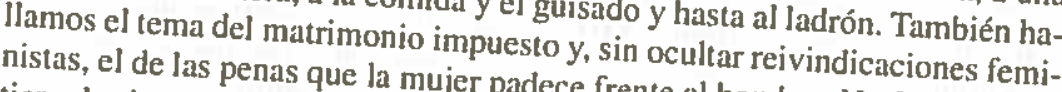
nistas, el de las penas que la mujer padece frente al hombre. No faltan la crítica a la situación social actual, las esperanzas de paz y el deseo de un futuro
mejor.

En el segundo grupo, es decir, en el de temática especificamente judía y sefardi, hallamos poemas que exaltan al Dios de Israel y a la festividad del sábado, que se inspiran en la religiosidad judía y adoptan forma de oración.

\footnotetext{
${ }^{2}$ Existen en cl panorama poético sefardí otros autores. El hecho de que no Jos ciEsperamos poder ofrecer en otro sean merecedores de nuestra atención y estudio
} 
largo de la historia y que abordan las vejaciones y agravios padecidos en la segunda guerra mundial, en los campos de concentración nazis, en el holocausto. A éstos hay que sumar aquellos en los que el poeta recuerda su pasado español, más alguno cuyo tema es el renacer de la lengua sefardí como el ave fénix.

Hay poemas que manifiestan entronque con la más castiza tradición poétíca de la época de pre-extinción. En este sentido hay que decir, en primer lugar, que, por ejemplo, en determinados poemas de Isahar Avzaradel como 'El pranso' ('El banquete') ${ }^{3}$ resuenan formulaciones de coplas como 'El debate de las flores' $y$ 'El debate de los frutos' y de la de 'Los guisados de las berenjenas ${ }^{+4} ;$ y en 'El apartamento i el vizindado"s hay perduración del subgénero de la poesía 'humorística' tan frecuente en la prensa periódica; algún poema de David F. Altabét suena en ocasiones como las quinot (hb. 'endechas') clásicas'; y formulaciones, imágenes o poemas enteros, por ejemplo 'Edut' (hb. 'Testimonio') de Avner Pérez", y en menor medida algunos de Altabé, no se entienden debidamente si no se ha dedicado largo tiempo a meldar las obras clásicas de la literatura en ladino. En segundo lugar, que ciertos poemas de Matilda Koén Sarano ${ }^{9}$, de Rita Gabbaï-Simantov ${ }^{10}$ y de Iko Konorti" tienen un lenguaje poético semejante al de la mejor lírica tradicional. Y, en tercero y último, que en Margalit Matatiahu, a quien dedicaremos la segunda parte de este trabajo, en Clarisse Nicoïdski'2, Iko Konorti y Rita Gabbai hay un intento, ocasionalmente bien logrado, de hacer poesía 'inte-

'J. B. ROSA, Sepharad '92; Antología de autores en lengua judeo-española, Valencia 1992, pp.44-45.

^E. ROMERO, Coplar sefardíes. Primera selección, Córdoba 1988, pp. 147-165.

'J. B. ROSA, op. cir., p.64.

- Vease The Sephardic Scholar 4, 1979-82, 133-135.

'Para mejor conocimiento de las endechas en judeoespañol propias de la conmemoración de Tis á beab (' 9 de ab' = julio-agosto, día de luto por excelencia para los judíos) vease E. ROMERO y I. HASSÁN, 'Poesía luctuosa judeoespañola: Quinot paralitúrgicas', Proceedings del IV Congreso Mundial de Estudios Judíos, Jerusalén, 1980, pp.7-16; de los mismos autores 'Quinot paralitúrgicas: Edición y variantes', Estudios Sefardies 1, 1978, 3-57.

'En Verdjel de mansanas, Poemas. Yeriot 1996, pp.62, 64 y 66 (sección 'Por las careras').

'En su haber destacan numerosos libros de recopilación de cuentos y consejas tradicionales. Su labor poética se haya publicada en revistas como Aki Yerushalayim. de Isarel, que dirige Moshe Shaul.

${ }^{10}$ Vease su poemario Quinientos anios despues, Atenas 1992.

" En Avia de ser... 'Poezias', Pedasikos de la vida, Israel 1994.

"En su libro de poemas Lus ojus las manus la boca / Eyes hands mowth, Sephardic poems with translations..., Loubressac Bretenoux 1978. 
Ana M. Riaño López y M. "Marcos Casquero

rior', entendiendo convencionalmente por tal aquella que consigue efecto poético no mediante recursos formales (rima, medida, estructura, ritmo) o verbales, sino por Jas imágenes o conceptos que lo verbal expresa.

Al margen de sutilezas de corte estético, lírico, técnico o documental, el valor fundamental que en el plano literario atesoran los poetas sefardíes contemporáneos es el de producir, como frutos de la constancia testimonial y del ahondar continuo en sus propias huellas para que nunca se borren, las casi únicas muestras recientes, hoy, del quehacer literario sefardi. Más aún: son un ejemplo de supervivencia literaria a la aniquilación padecida por los sefardíes en la segunda guerra mundial y en el holocausto nazi. Y más: son la esperanza de no haber llegado al final de esta literatura, pues cada vez que un sefardi escribe un poema en judeoespañol es claro que pone de manifiesto inspiración y no expiración, que produce alumbramiento y no muerte. nea nos adentramos en la segunda parte de este artículo, en el estudio de la obra poética escrita en judeoespañol por Margalit Matatiahu.

\section{2) Estudjo sobre una poetisa sefardí de hoy: Margalit Matitiahu'3}

En los comienzos de este trabajo hemos adelantado los motivos que nos han llevado a elegir de entre los poetas citados a Margalit Matitiahu. La poetisa, hija de padres oriundos de Salónica que escaparon del holocausto nazi y se refugiaron en Israel, y descendiente de sefardíes leoneses, nació en Tel Aviv. Estudió Literatura Hebrea y Filosofía en la Unjversidad de Bar-Ilán. Su amor por la tradición sefardí la llevó a estudiar y difundir, durante veinticinco años, el folclor de las comunidades judeoespañolas de Grecia. Actualmente investiga la prensa de Salónica escrita en sefardi entre los años I860-1940. Participa en numerosos congresos internacionales y ha recibido premios literarios, como el internacional Fernando Jeno 1994, del Comité Central de la Comunidad Judía de México, el internacional de Literatura Ateneo de Jaén 1996 y el Premio de Literatura y Creación del Primer Ministro 1999, que es el más importante que se concede en Israel. Es, además, miembro de la Academia Mundial de Arte y Cultura -de la que fuera

${ }^{13}$ Advertimos al lector de que hallarí escritos, a lo largo de este estudio, con diversas grafjas los títulos de los libros, sus secciones y los poemas que ellos contienen. Esto es debido a que hemos respetado la heterogeneidad con que, en este sentido, ha sido publicada la obra de Matitiahu: por un lado, con la grafía original de la autora $y$, nol actual realizadas por el profesor lac de la escritura del judeoespañol a la del espa- 
nombrada Doctor en Literatura-, del Pen Club Israelí y de la Federación Israeli de Escritores.

Tiene publicados en Israel cinco libros en hebreo, cuyos títulos, traducidos por la propia autora al judeoespañol, son los siguientes: Por el vidro de la ventana (1976), El no selensio veraniego (1979), Kartas blancas (1983), Eksposada (1987) y Eskaleras de media notche (1995); Kurtijo kemado (1988) y Alegrika (1992), bilingües en sefardí y hebreo; Matriz de luz (1997), en sefardí. En 1997 publicó en España Vela de la laz, que reúne poemas editados con anterioridad en sus obras en judeoespañol. Este libro, dedicado "a todos los sefarditas de aquí y alla", se estructura en siete apartados: Curtijo Quemado, Los visajes, Alegrica, Cartas, Simientes de amor y Matriz de luz, poemas; y Las escaleras de media noche, escrito en prosa ${ }^{14}$.

El eje temático constante de su poesía es la nostalgia, resultado de un sentimiento de desamparo por la pérdida de personas queridas, especialmente de su madre. Asume entonces la vida como una pasión y como una doble búsqueda: de las raíces familiares, por un lado, y del objeto de sus sentimientos, por otro. La falta de asideros familiares y amorosos se manifiesta con fuerza; la sensación más evidente es la de una mujer en busca de un pasado vivido que añora y de otro que intuye; ambos están en los recuerdos. Tal vez sea el vacio interior de la poetisa lo que trata de llenar. Es una búsqueda para trascender la realidad. Existen repeticiones y anáforas que colaboran a esa sensación de búsqueda angustiosa: 'el tiempo pasado', la 'chiques', 'los nombres', 'las solombras', 'saltando entre luz y tiniebla', etc. La búsqueda llega incluso hasta las sombras y los muertos, que tal vez puedan darle una respuesta: la madre, fundamentalmente, tíos, primos e incluso algún rostro contemplado en los viajes. Pero no la obtiene. Sólo se comunica con ellos međiante un diálogo en el que la presencia de la voz poética deja al descubierto sus sentimientos ante el silencio del protagonista receptor. Sin embargo, consigue descubrir sus orígenes sefardíes: Puente Castro, en León.

Junto a este núcleo temático y como consecuencia de él, en la poesía de Matitiahu aparecen otras constantes: los viajes, el amor, las personas, la naturaleza y la soledad.

El tema del viaje pređomina en los poemas de Curtijo quemado, Cartas y Matriz de laz, especialmente en el primero. Los lugares visitados son Grecia

"Vela de la luz, León 1997. El libro se cierra con cuatro apéndices: dos reproducen los prólogos de Shmuel Rephael a las ediciones primeras de Currijo Quemado y Alegrica; otro es de Alejandro Valderas Alonso sobre la diáspora; el último, de Ana I. Conejo e Hilario Franco, sobre la editora del libro: la revista leonesa Ponteaérea, que dedica su quinto nümero al encuentro de las tres culturas bajo el título Jerusalem Córdoba-León. 
y España. Hurgando en los recuerdos, vislumbra un pasado sefardí y comienza la búsqueda de sus raíces. Curtijo Quemado es, según la autora, un homenaje a su madre, muerta en abril de 1986, y a todos los judios víctimas del nazismo. Tiene una estructura lineal, clara. Se trata de las impresiones, más que de la narración, de un viaje, real y poético, de la autora a Salónica, patria originaria de sus padres, en los meses de julio y agosto de 1986, y se cierra este apartado con dos poemas sin fecha que se corresponden con la vuelta a casa. La motivación real del viaje es una visita de diez hijos de supervivientes del holocausto nazi a las comunidades judías de Grecia. La motivación no explícita del viaje es el anhelo trascendente de recuperar un pasado sólo vivido a través de la memoria de la madre ("meso las memorias plantadas en mi por mi madre"). Fallecida ésta, desaparece el objeto de su amor; pero queda el recuerdo (y las palabras en el aire: "las voses de lo pasado quedaron en el aver"), y Matitiahu busca lugares reales en los que revivirlo y perpetuarlo mediante la evocación. La autora nos recuerda la idea de Nietzsche de la 'vuelta eterna': revive para ver volver, con un afán de retorno perdurable, etemo. En algunos poemas se produce el espejismo de haber encontrado algo, de tocarlo, de darle vida para poder retenerlo. Pero su viaje continúa, porque sólo hay vacío (los muertos, la guerra, el amor), miedo, oscuridad. La conclusión es el fracaso, la resignación, la soledad. Está encadenada a la realidad y se detecta una cierta aceptación estoica, aunque al final del libro se observa un esperanzador signo de lucha al vislumbrar "rayos de sol" en el "hielo del invierno":

En el camino a Jerusalem

Rayos de sol se encolgaban

En el yelor del envierno.

La vedrura reflectaba en la claridad

Tocando la tristesa de mis ojos,

Bajo el sielo blu

Un combale de colores nasia.

Truviada de mis penserios

Via que mis palabras alborotadas

Caian en lo vasio

Tetereando como el eco que disia sin quedar:

"Una sulusión se debe de topar..."

("En el camino a Jerusalem")

El motivo poético es el resultado de una lucha entre la permanencia y la nada, entre la vida y la muerte; es la rebelión contra la soledad y el dolor mediante la fusión con la naturaleza, actitud que la sitúa entre los románticos, como Bécquer y Cernuda. No faltan resonancias de Hölderling cuando, al vi- 
sitar la moderna Grecia ("Aquí esta enterada la simiente / del arte y de la sabiđuria"), rememora la desaparecida civilización helénica y constuela su soledad en la conjunción con la naturaleza y la mitología. Como le ocurre a ella, "Las colonas del templo se esforsan / a detener el esprito antiguo / que el aire y la tempesta lo arebatan" ("Greec"). La Grecia clásica y su pasado personal son sentidos como un mundo edénico.

Matitiahu vive tanto en lo pasado como en el presente, y su poesía encuentra su mayor fuerza en la rememoración: "Con la marca de dolor en el puerpo, / Como la mesusa / Besar besar y acodrar". Su visita a Salónica le hace experimentar con angustiadora exactitud la misma sensación que unos cuarenta y cinco años antes habían experimentado sus antepasados, víctimas de los nazis. La autora se siente desgarrada por los horrores que padecieron y lo recuerda en "La plasa de la libertad":

La plasa onde los judios de Saloniqui fueron arecojidos

$Y$ mandados a los campos de consentrasion.

En la plasa posaba la cayades

Ma muestros oyidos sintian el ruido que subia del tiempo pasado.

Las ventanas de las casas mos miraban con ojos estranios

Y una negrura enloquesida paresia abashar

De las aguilas arrebatadoras vistidas de maldad.

La plasa mos asia sinios invesibles,

La cayadez corria gritando en muestras venas.

En la lonjura, la mar quedaba blue como el sielo Ma muestros mushos se empretesian.

"La plasa de la libertad"

Topa oy abrigo basho la solombra de los arboles

Abocados por el pesgor del enverano

$Y$ de una manera de libertad timida

Continua a sircolar el movimiento,

Ma de las ventanas que siempre van casando la luz

Nunca no podra fuir la escuridad.

Esta memoria de sensaciones es reflejo de su sensibilidad. Y su estado de ánimo queda reflejado en un léxico lleno de connotaciones y en los recursos estilísticos: paradojas y contrastes (gente / soledad, alegria / tristeza, libertad / prisión, "la alta dolor que se topa en las onduras". "se asendio el escuro sol", "la cayadez corria gritando en muestras venas", luz / oscuridad, movi- 
miento / quietud); sinestesias significativas (sombra, oscuridad, azul, negro, silencio, ruido); campos asociativos opuestos que se interrelacionan y en los que se identifican las sombras con lo negativo y las luces con lo positivo.

Se trata, por tanto, de un viaje conocido, lleno de recuerdos personales vividos en la memoria transmitida por la madre, pleno de nostalgia y de dolor por el pasado tormentoso que vivieron los judíos de Salónica, y que se confunde con el dolor del presente por la reciente ausencia materna. En su madre están las raíces poéticas de la autora (tambiên aquélla escribió poesía en griego: "tu padre planto en ti simiente de poesía") y el origen sefardí (siempre conservó el apellido León). La madre, como a Jorge Guillénn"s la suya, le regaló el ser, el vivir y el lenguaje. Su emoción brota ante la tumba:

\author{
Antes de la partensia al portal de tu chiques \\ Vine madre mia \\ A batir enriva la piedra de tu casa eterne] \\ $Y$ desirte que me vo ande se crio tu alma \\ Ande tu padre planto en ti simiente de poesia. \\ Me aserco de tu sufriensa cayada \\ $Y$ de las piedras que no tienen luz \\ Ma todo no fue en vano \\ Vo a murmurear en tu oreja de tierra.
}

("Antes de arivar a Saloniqui", julio, 1986)

Todo el viaje está plagado sentimientos, especialmente el recorrido en el tren (que le recuerda el 'camino de tormento' de los judíos, "la línea de enfermo'), la calle de Salónica en la que creció su madre y la Plaza donde la hicieron prisionera. En ocasiones, el resultado del viaje parece positivo: la autora se siente fortalecida por el recuerdo materno, según se observa en "Solombras palidas": "Como criansas tocadas de lumbre / Venimos tus jjos, / $Y$ tu esprito de mas en mas / En nos se enfortese".

La contemplación del cortijo familiar quemado durante la guerra tiene un efecto catártico que se refleja en el poema "Curtijo quemado". La imagen real de la casa destruida suscita un sentimiento de purificación y liberación de los recuerdos que perturbaban a Matitiahu. El lenguaje cargado de simbolismo refleja toda su angustia ('ajena', 'estranio', 'pretas', 'desorden') y la superación liberadora provocada en su interior: lo negro ha dado paso a colores que brillan, toda la turbación de su espíritu encuentra calma y seguridad, el silencio reina:

"Véase la primera dedicaloria de Cántico. 


\begin{abstract}
Me topaba en tierra ajena
En un estranio curtijo

Arodeada de baracas pretas

Y de colonas en desorden espardidas.
\end{abstract}

\author{
Dentro mi lo sabia \\ Que en otros lugares \\ Las colores brian \\ Y el selensio reina \\ Con calmesa y siguridad.
A mi esprito queria dar
La libertad de fuir,
El curtijo quemado
Me asia sinios
Sin disir.

Estos tres últimos versos significan el inicio de una búsqueda real ("en otros lugares") de algo que estaba en su inconsciente ("dentro mi lo sabia"): sus origenes sefardíes. La visita al país natal de sus padres y a las comunidades judias exterminadas en el holocausto, "me provocaron una fuerte convulsión interna y escuché una voz interior hablándome en ladino"'t , dice la autora. Y es en Salónica donde comienza la búsqueda ("me topaba en tierra ajena"), donde rastrea ese pasado y descubre que procede de Puente Castro, León. En numerosas conversaciones, Matitiahu ha manifestado la importancia que para ella tiene el saber de dónde viene, quién es y adónde va. Constatada su procedencia, inicia otro viaje, a España, cuyas impresiones relata en Matriz de luz, poemario del que hablaremos más adelante.

El sueño esperanzador parece vana ilusión. El último poema de Curtijo Quemado, "Tomo a mi casa", es un reencuentro con su soledad: "Vo abrir la puerta serada / y el selensio va gritar de la pared. / Torno a ver mi casa / una suma de vida en ella transpara, / el horror camina sobre mi espalda / ase alevantar mis cabeyos".

En Cartas, conjunto de cinco poemas, la autora continúa el tema de los viajes y la evocación del pasado. "En las calles de Atenas", revive recuerdos de su niñez, de su lengua, de su casa: "En las cayes de Athena / yevaba la valija de mi chiques: / ella conservaba nombres, colores y golores / que se desvainaban como cartas de mi memoria". Busca el pasado en las cosas y en las gentes: "Fishando la mirada en las fachas de la jente / buscaba restos de fisonomias / que vivian en los ojos (agora muertos) / de mi padre y mi madre".

${ }^{10}$ Arboleda, Palma de Mallorca, VI, n³0, p.755. 
En "El museo judío" de Atenas, son los restos 'rescapados' del pasado los que la conmueven: "Pedasos de ropa, vistidos, libros viejos y arugados". Pero la mayor emoción le llega del "chico medalion / del tiempo de la nona de mi nona / que en mi garganta tanto brilyaba". Siempre los recuerdos y la nostalgia. Y siempre el paso del tiempo sugerido por los elementos de la naturaleza, como en "Volos".

El contraste mayor entre el pasado y el presente, imagen del estado en que se encuentra la autora, se produce en la visita a la casa de su infancia, ya ruinosa. Esta visión provoca tristeza y desconcierto, pues evidencia un reencuentro con el pasado ya destruido, y que se materializa en la casa vacía, en la hierba envejecida, en el árbol ahora seco. El poema puede interpretarse como una alegoría del paso del tiempo y su efecto destructor. La estructura intema del poema se asienta sobre una gradación de lo general a lo concreto que le sirve para expresar el desamparo en que se encuentra (el árbol representa a la madre) y la añoranza de la infancia (simbolizada en "la casa de mi chiques"):

\author{
En el lugar \\ Onde estaba aparada la casa de mi chiques \\ Ya se enviejisio la yerba, \\ Y en lo vasio de sus camaretas rubinadas \\ Siento ainda las voses. \\ El arbole que basho de su solombra parfumada \\ Topaba abrigo \\ Esta agora seco sin ojas.
}

La yuvia que caye, el camino,

La baranda...

No se en que tiempo me topo...

Si es maniana

o otro dia que me pasa...

("La casa de mi chiques")

La poetisa ha llegado a la mitificación de ciudades, de su infancia, de su inocencia perdida. Los espacios visitados en esta serie de poemas evocan un pasado familiar con el que anhela encontrarse para revivirlo. Pero surge la desilusión y la melancolía al descubrir que ese pasado sólo vive en los recuerdos, en las piedras, en el paisaje y, fragmentariamente, en los museos. Pretende, entonces, dar presencia poética a las cosas y a las personas a través de las palabras que fluyen de sus sentimientos y emociones.

Junto a los recuerdos del pasado, reflota el dolor del presente. Es significativo que el último poema de Cartas, "Caminos de fuego", esté dedicado a su hermana Eti, muerta por el cáncer en 1996: "La poezia fue escrita cuando 
estava luchando por su vida. Era mujer jovena muy ermoza", nos explica la autora en una carta. Otra vez la lucha. Los "caminos de fuego" se trasladan al presente, en el que confluyen las emociones recordadas y las vividas:

Tan palida, dientro la dolor,

Tus muvimentos se unden en el selensio

Tu no me ves como te veo yo

Detrás de las velas y los anjos.

Pareses de toparte en un lugar

Onde vas caminando avagar, como una estatua,

Tornando ta espalda a la tempesta,

Subiendo en los caminos de fuego

En quedandote entesada, $y$ con tanta calmesa.

\author{
Agora \\ Tambien en este viaje \\ Por siguro que podras resistir, \\ Como cadenas de fiero \\ Es tu coraje.
}

En Matriz de luz (1997), su último poemario, retoma el elemento central de los libros anteriores: la memoria del pasado, especialmente de la madre, los viajes, las personas, el amor. Estos diecinueve poemas son una recuperación del mundo poético anterior y de los símbolos de la desolación inmediata, cargados de una mayor emotividad y lirismo. Tras más de diez años, sigue presente la imagen de la madre, con la que ahora se funde y a la que dedica este sentido y significativo poema:

Me visto tu cara sobre la mia, $Y$ con tus ojos veo tu ermosa sivdad natal.

La tristesa y la maravia te envelopan

En viendo lugares que ya no los conoses mas.

Te mostro las cayes y las forteresas,

Y espando mi mano para que tu de nuevo

Puedas las piedras tocar.

El camino me yeva verso la Tore Blanca,

Con tus jovenos pieses subo asta la punta alta,

Y tus memotias se ajuntun a las mias.

Con tu vos me siento prononsiar nombres

Conosidos por ti,

Sus figuras se areviven cuando les conto por tu vida.

En subito, reflecta en mis ojos tu dulse sonrisa.

("Me visto tu cara sobre la mia") 
Es imposible resucitar un pasado mitificado que sólo pervive en la memoria. $Y$ a ésta se aferra cuando siente el vacio causado por el paso del tiempo, como manifiesta en este tremendo y significativo poema:

Una mano de esito

Espando a la memoria

Alando en ella siete cabayos feridos

Saltando entre luz y tiniebla.

El tiempo

Es una eluenga cortada,

Enfrente de mi

Se debate y desparese.

La memoria se espande,

Deviene velas palpando,

Yo me encolgo en ellas

Entregandome a la direxion

Del corriente foturo.

Subito

Las linias del aver se vasiaron del oxijeno.

Mi puerpo viene acudir,

Va leshendo una resha

Por mantener a la memoria

En el momento de la caida.

("La memoria")

Nostalgia del pasado y necesidad de perpetuarlo. En "Urias de envierno", la autora contempla un paisaje marino en invierno (el presente) que convierte en una alegoría de su propia vida: ella, como pájaro en la playa, picotea en el pasado ("mar del enverano") para verificar la existencia:

Los pasharos

Abasharon a las urias del envierno,

A picar

Restos de mar del enverano.

Sobre la arena esponjosa

Van undiendo sus bicos duvdosos

Gostando la sabor

$Y$ verificando la existensia.

Vuelta siempre al pasado vivificador. Por ello, emprende, como dijimos supra, otro viaje, que recoge en Matriz de liz, para reencontrarse con un pa- 
sado más remoto, con la Sefarad de sus origenes leoneses retenidos en la memoria de la madre, depositaria y transmisora de la memoria familiar. Cada persona lleva con ella su pasado y Matitiahu es ahora la nueva depositaria y la encargada de revivirlo. Recorre las costas norteñas de Cantabria y el centro peninsular. Encuentra una España hermosa que contrasta con su turbado espiritu, con el vacío interior. Y surge en ella un estado melancólico que le hace gritar la soledad en que se encuentra. Así, el solitario paseo al amanecer por el puerto de San Vicente de la Barquera desata sus pensamientos ("Estaba caminando en el selensio, / respirando la finesa de la maniana, / atando mis pensieros entre las manos de los pescadores") mientras contempla, por medio de los sentidos, la ciudad. La descripción nos transmite esas sensaciones ("el frescor de la madrugada", "la luz de la maniana pintaba con colores", "las casas anturadas de rosas", "la golor del café"), apoyadas con aliteraciones ("sobre el ponte viejo solo el viento pasaba, / mis pasos avagarosos asian conosensia con el camino. / Las barcas se cunaban sobre las ondas como cunas de criaturas") que contribuyen a reforzar la impresión de la imagen. Al medio día, la belleza del paisaje cambia y se identifica con él:

\author{
Y se descubría la arena con su desnudes \\ Igual que mis pensieros reflectados por la natura, \\ Las barcas paresian flores amurchadas, \\ Como puerpos sin alma. \\ La tristesa se aunaba con la mia, [...] \\ Un troquido sirculaba en mi cara
}

Sintiendo la ermosura y la tristesa

Que se plantaban en mi.

"Inspiración" es el resultado de su visita al Cabo de La Nao. La contemplación del mar azul, del movimiento de las olas, de las montañas y del paisaje en general, le impresionan de tal manera que hacen que se sienta transportada por el viento para proclamar la belleza de España ("Dientro el viento, enspirada, volando, / sobre las puntas de los piniascos / vo describiendo con mis ojos en el sielo / la ermosura de la Espania"). Hermoso poema impresionista que nos sugiere las mismas sensaciones.

En su viaje, aparece el tema de la patria perdida, de la diáspora española, mirada sin rencor; con amargura, pero con serenidad:

Cresi de tu puerpo

Que me dio raises

Que me yevo al fondo de mi saber. 


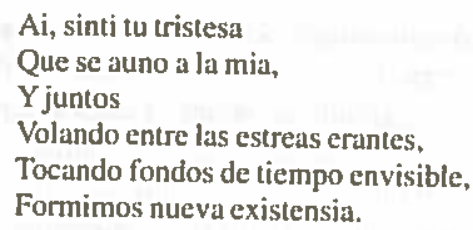

Flores doloriosas

Nasieron de palabras,

Relampagos asendieron el esprito,

Plantaron siejos en nuestrus entranias.

("Cresi de tus raises")

Ese dolor lo manifiesta claramente en el poema "Octubre". Los recuerdos del pasado judio aparecen en su viaje ("Toledo te ase sinios invesibles / como las rosas de Lorca / que se enfincan como cuchios en el aver"). Acalla su rabia interna ("y asimilas tus gritos / en los undimientos de las tripas blandas") por el incomprensible hecho de la expulsión y, al contemplar que ahora es diferente, decide enterrar el pasado:
[...] Las piedras en los caminos
Bashoel sol
Ya no conservan mas la rabia
$Y$ un lonjano octobre,
Toma a enterarse
En tierra de demandas.

Con el viaje a España, ya se ha hecho patente ("matriz de luz") para Matitiahu lo que estaba oculto en su interior: su origen sefardi, mantenido de generación en generación y transmitido por su madre, y que es asumido sin resentimiento. En cierto modo cumple sus objetivos: saber quién es y de dónde viene. Ahora se dedica a disfrutar del encuentro con España. Sus poemas perpetúan momentos agradables: los sonidos de una guitarra española en una noche ya lejana y el recuerdo nostálgico de alguien que apareció y por el que se sintió atraída, tal vez hechizada por el momento, por el ambiente; las calles antiguas de Madrid, la Plaza Mayor, las tiendas, las comidas, la historia y la agradable compañía de las amigas: lodo ameniza la conversación y se presta a las confidencias. La simpatía del recuerdo da pie a paradojas ("un ruido mudo') y juegos de palabras ('Pilar era un pilar', 'pasos... pasaba').

En el intento de reconstruir su universo a partir de los recuerdos, Matitiahu poetiza sobre las personas que le fueron próximas: rostros, lugares, actos alcanzan sentido pleno a través del lenguaje de la poetisa. Se centra en la vida cotidiana del pasado, en las gentes, en momentos de la infancia y en las cosas elementales de la vida. La búsqueda y la reconstrucción representan 
un intento de llenar el vacío. Se sirve de la memoria y de la intuición para llenarlo.

En mis ojos transparan los anios Formando direxiones yenas de visajes

Que van corriendo y metiendo

Los recordos en empenio.

Como sones y golores

De un manadero suben las figuras

Ajuntandosen a las trupas

De serenas enloquesidas.

("Los visajes", A.)

Dos breves poemarios tienen este tema central: Los visajes y Alegrica. En ellos, con unos cuantos trazos prectsos cargados de significación ("de luto", 'olor a ajo', etc.) va configurando al personaje y entrañăndolo en su espacio, en su momento, en su tiempo. Unas ligeras pinceladas bastan también para marcar un ambiente que vemos y sentimos plásticamente.

La familia aparece en Los visajes, "los rostros", poemario que dedica a sus hermanos con el deseo de compartir los recuerdos con-vividos. Para Matitiahu, la familia es fuente de indudable valor de su pasado y revivirla significa una especie de continuación eterna. Por eso, en versos de distinta exiensión, la evoca con ternura, con sonrisa, con nostalgia. Unos pocos tếrminos bastan para trazar y singularizar la figura, para reflejar exactamente el ser, para desvelarnos la anécdota retenida en su alma, para rescatar una leve parte de la vida. Y todo ello lo llena de intenso lirismo:

Tia Dudun y tia Leu

Asentadas en el curtijo de la casa

Asperando la solombra de la esperansa

Que las abrigue otra ves.

En los cabeyos de tia Dudun

Se conservaba la cayadez

Como una furia desatada. [...]

("Los visajes", B.)

Son hermosos los versos con que recuerda a su tía Lea en el poema C: "[...] mascando las palabras con mudez/ sin saber artura. [... ] De su espalda doblada una mano espandia / para detener el baston de la muerte". Con tía Diamante y tio Shabtay revive recuerdos, historias de Salónica y cantos evocadores. Yudachi Bahar, "el hombre del canapé lo yamaban", murmuraba oraciones y asustaba cuando se enfadaba. Con "Sunhula", la lavandera, des- 
cribe con pinceladas breves el proceso del lavado de la ropa. A "Tía Ester" la recuerda vieja, lenta, y con olor al ajo que comía; sentada durante horas, cuerpo pesado, vestía de oscuro, gruñona con los niños que jugaban y a los que amenazaba con su gordo dedo. Cuando murió, su olor se quedó en la silla de paja y su sombra amenazadora, en la pared. En "Las paredes del tiempo" Matitiahu nos transmite recuerdos de una habitación que refleja pobreza y en la que alguien "siempre vistida de viejas ropas / una reyna paresia". "Rubén Rubenico" revive una tierna historia de amor que continua más allá de la muerte.

Con Alegrica Matitiahu se aleja de las añoranzas familiares y de la bưsqueda de raíces históricas. Fruto de recuerdos subyacentes, Alegrica "es una figura enventada, que le di vidas. Es como un simbolo que auna en ella tres generaciones en una forma metafizica", nos comenta la autora. Está constituido por seis poemas que recuerdan con melancolía momentos de la vida de Alegrica en tres edades: "la ninia chica" (poemas A, B y C), "la joven ninia" (poema D) y la mujer (poemas E y F). La infancia se desarrolla en un mundo en el que la luz y el color se identifican con el mundo inocente y feliz de la niña soñadora, llena de alegría e ilusiones:

El panorama gravo lo vasijo

Como restos de muvimientos

En el tiempo.

"iAlegrica!”.

En las onduras de la absensia

Se sintia la vos caresandola

Como el sol a un campo

Escuro y entesado.

Y Alegrica -entonses-

Ninia chica

Envuelta en las ilusiones

Enrimada con su palma

En la rotura de una pared

Cuajando cl tiempo.

(Poema A)

La autora utiliza reiteradamente el continuo grito de llamada de la madre, " „Alegrica!”, (que aún permanece en los oídos de la protagonista, como constatamos en el poema E) para recrear las situaciones más variadas en las que Alegrica está absorta en sus pensamientos y juegos: la compra del viernes para celebrar el shabat, la nobleza de la casa, las ricas telas de los vestidos y de la lencería, el perfume "del jasmin y de la agua rosada". Alegrica vive feliz y hechizada, sueña y sólo piensa en vivir el momento: 
[...] Parfumada del jasmin y de la agua rosada

En sus ojos bailaban ilos de oro y plata,

Envuelta de tules y almadas de organdin

Subidos de la solombra del esfuenio

A la cara del sol

Por el momento vivir...

(Poema C)

He aquí una significativa elipsis con la que Matitiahu corta el relato de la infancia de Alegrica, vivida en tiempos de paz. Sólo un poema, el poema D, basta para narrar una juventud destruida muy pronto por causa de la guerra. La trágica muerte de la madre y la tristeza de la joven están sugeridas con precisión:

La joven ninia

Alegrica

Con los cabeyos ondulados

Caminaba en la caye de guera

Indose a la lison de piano...

"¡Alegrica! - ¡torna a casa!"

La yamaba su madre con vos caida.

Y Alegrica

Comoenfichisada

Mirandose de si para si

No quedaba de tanier los sones de Chopin

Que su tristesa apagaban.

Junto a este tiempo evocado, aparece el tiempo presente en los dos últimos poemas en los que Alegrica ya es mujer. El contraste entre ambos tiempos viene marcado por el paso del pretérito perfecto al presente. La guerra arrebató a Alegrica su mundo de inocencia y vive ahora al borde de otro que Matitiahu define, con metáfora manriqueña, como "en las oriyas del rio escuro". En el aire aún resuena su nombre pronunciado por la madre. La autora muestra la situación anímica actual del personaje poético, una tristeza que contrasta con su alegría de nin̄a:

Alegrica

En la escuridad munda el sielo

Y orasiona,

La pared a su lado, se empapa de su vos amudesida.

Al espuntar la manianada

Sale verso la caye 
Y cubre con el sol

La tristesa en sus ojos.

(Poema F)

Los alegres colores de la edad de la inocencia se han trocado en oscuros y tristes. Los objetos que tanto agradaban a Alegrica en su infancia ya no aparecen en las restantes etapas de su vida, pues lo inanimado sólo sirve en función de lo animado ${ }^{17}$, que se ha convertido en materia de dolor. Matitiahu se sirve de su habitual simbología para mostrar el estado del espíritu.

El tema del amor ${ }^{17}$ Io trata en Simientes de amor y en numerosos poemas de Matriz de luz que describen un descenso a las profundidades del yo. Se mantiene en su tradicional línea poética intimista y evocadora de paraísos perdidos. El poema "Amor" nos ofrece Ia concepción que la autora tiene del mismo:
¿Qué hace un amor?
Mete miel sobre la lengua,
salsa de dolor en los ojos
temblor de fuego en el cuerpo
y una pasión loca que aciende el saber.

Suelen ser versos breves en los que la autora nos muestra su estado de ánimo, generalmente en contraste con lo real alegre y hermoso. Se detecta una tierna melancolía que proviene de los recuerdos, de su soledad y de un amor insatisfecho. Pero no existe ningún patetismo. El amor cantado está cargado de idealización y de una cierta sensualidad que emana de sus sentimientos ${ }^{19}$. La melancolía procede a veces de una indefinida sensación:

"Esta idea se repite una y otra vez en Mundo a solas, de V. Aleixandre, donde el tema de la no-existencia está presente en casi todos los poemas; y la actitud de la protagonista, Alegrica, nos ha recordado versos de este libro, como Senir diariamente que la vida es la muerte (de "Bulto sin amor").

Aunque no lo incluimos en nuestro estudio por tratarse de un relato en prosa, en Las escaleras de media noche la autora narra una historia de amores ocultos con un enotme lirismo. En él están presentes las mismas imaigenes melancólicas que en su producción poética. Baste como ejemplo el parágrafo final del relato: "El salía verso la madrugada. Ella tomaba de nuevo a la escuridad su noche".

${ }^{19}$ Ejemplo de esta sensualidad es el poema "Matriz de luz", del que se desprende el acto amoroso tras el que llega el sosiego; la protagonista, adoptando posición fetal (de la que podría hacerse una interpretación en cierto modo freudiana), se imagina "en la matriz de la luz" de una madrugada que desearfa eterna. También el poema "Exposada", que termina con estos versos: Muvimientos exclamando/nacidos de nuestra alma y cuerpo / profondizan el amor. 
Pasos de otros siecolos,

Ruidos desconosidos suben a mis oidos,

$Y$ no los puedo quedar.

¿Onde me topo?

Las demandas se esparsen en el aver.

Me veo volando,

Tierra y sielo me envelopan.

Muntanias alsan sus alturas

Tocando las sesones

Que rodean buscando nido.

Sin topar reposo

Van tocando las colores

Del cosmos eternel.

("Pasos de otros siecolos")

Otras veces nace de la carga del pasado que condiciona su presente. Ambas le provocan desilusión:

Meldo tus poesias Cavafi

Para emosionarme de tu desesperasion,

De tus palabras que me fieren,

Que me retoman al sentro de la existensia

Para saber que piedri

Como piedrites tu

Los dulses labios de ln ilusion.

("Labios de la ilusion")

Otras, en fin, de la rutina y el desencanto:

Siempre las mismas escaleras, siempre la misma mar en el tejo. y el sol se va rompiendo. [...]

("Plantas vagabondas")

Uno de los poemas, "No me llames loca", no puede ser más explícito sobre la raiz de la melancolia de la poetisa: ama desesperadamente (nótese el uso de la hipérbole de los últimos versos), pero:

Truvian mis noches

Gotas de vino amargo.

No me yames loca

Si te digo 
Que ay siecolos

Que te amo.

El mismo sentimiento informa "En mi vos siento la tuya":

En mi vos siento la tuyas

Que me va contando

$Y$ me va disiendo lo que no se

Ma lo queria.

Te siento dientro de mi

Como chios de arboles

Afrisionados de luvia,

Orasionando.

Los cabos paresen prensipios,

Los caminos se alongan

Asta tocar el orisonte.

Siempre te veo

Meso mis manos

Meso mis unias

Meso mis ojos

Que yevan un amor

Sin fruto.

El desamor (no en ella: "No, no es la flama de mi alma / que se amató", como nos indica en el poema "La flama") lleva a la separación y a la soledad:

Después de todo

Quedimos los dos

Como una isla asolada,

Como rasgones en el tiempo,

Como dos continentes lonjanos.

Solo tú,

Sola yo,

Deseando la locura,

Deseando la pasión.

("Deseando la locura")

Y queda la añoranza constante: "Hay veces / que quiero de nuevo ser/la mujer que creció de ti..."; o "En la espalda del tiempo presente / aínda re- 
flecta un río colorado". A veces su dolor es tan grande que "Quiería ser nube", porque "ahí no golpean los momentos / con chíos metálicos. / ¡llusión!", nos dice en "El chío".

Comparte sentimientos con la naturaleza al más puro estilo romántico y el paisaje está utilizado con valor simbólico:

Ventanas de mar,

Ondas de temor,

Sielo serndo.

En las ondas el temor se cristalisa,

Las aguas devienen vidros

Rompiendosen

Dientro la luz de las urias feridas,

Ay

-El calor de tus penserios

Reposo en mi puerpo

Entregando un selensio paresido-

("Por la ventana")

Se desarrolla, en ocasiones, un contraste entre la realidad externa y la interna:

La manta gravo mi puerpo

Dublado dientro el selensio,

No, no siento el piedrisco,

No, no veo la escuridad,

Somos amorosos plantados

En la matriz de la luz

Al espuntar

Una madrugada eternel...

("Matriz de luz")

Silencio, pedrisco y oscuridad quedan anulados por la luz que irradia el amor como en un amanecer. Ya en su primer poemario, Curtijo quemado, aparecen estos contrastes entre la naturaleza y su espíritu:

Como un punio en el estomago

Se apunto en mi la manianada,

$\mathrm{Y}$ los rayos del sol se trocaron

En solombras.

En la camareta de los ijos

Se cuajo el muvimento

$\mathrm{Y}$ un reposo pesgado se asia cayer. 
Como un pasharo devine, buscando abrigo

Del yelor que desbrocho en el aver.

("El reposo pesgado")

Los elementos de la naturaleza presuponen en la poetisa un estado de ininterrumpida y máxima exaltación (detectable en sus deseos y esperanza de cambio) y una huella de tristeza y melancolía que no dudamos en calificar de neorromántica. Exaltación del yo, a través de cuya sensibilidad se percibe el mundo exterior. Esos elementos naturales con los que Matitiahu funde su alma proceden de evocaciones de lugares vividos. Unos son naturaleza física: el mar, la playa, las montañas, el camino, los campos, los árboles; otros son de impregnación sensorial: la luminosidad, los colores, los olores, las sombras, el ruido, el silencio. No faltan referencias del mundo mitológico. La naturaleza romántica de la autora determina la fusión de alma y paisaje.

Como en toda su producción poética, también en el amor Matitiahu añora anteriores situaciones de estado amoroso, como ya hemos señalado. Los personajes sujetos de ese amor son evocados, pero no existe una imagen definida:

Tu en mi estas asembrado

Y yo en ti esto plantada

Como la primavera sobre los arboles desnudos

Mos anvelopamos los dos

De las raises asta la cabesera

Venites en mi

Con simientes de amor.

("Venites en mi")

Ahora su estado de ánimo es gozoso y lo transmite mediante símbolos: 'asembrado', 'plantada', 'primavera', 'simientes de amor'; o 'creser”, 'calor", 'grito amudesido" (de placer y gozo), 'campos envisibles' del poema siguiente:

Atirada por tu mirada

Que ase creser en el puerpo

Palabras que yevan el calor en mis venas

Formando un grito amudesido

Que se esparse prononsiando tu nombre

En los campos eлvisibles

Que conosemos los dos.

("Tu mirada") 
¿Son estos paraísos perdidos los que añora? Mujer sensible, necesita el amor y de ahí brota esa melancolía que impregna su poesía y que guarda en su alma, aunque extemamente lo enmascare:
Pareses una mujer ulegre, me disheron
¿Ma por que tan tristes son tus palabras?
Cuala es la mujer alegre, ise la demanda,
La que tiene cara de risa, me disheron,
¿Quién disho que una mujer que riye esta alegre?
Entonses empesi a yorar.
Ma dientro mi me sinti riyendo
Al pensar como se puede a la jente enganiar.
("La mujer alegre")

$\mathrm{Y}$ es que, efectivamente, Matitiahu vive su soledad y su dolor a solas, como reitera en sus poemas: "En las paredes de mi camareta asolada / transparan los espacios de mi disierto interior": "siempre dientro el selencio"; o el significativo poema "En medio el mundo", en el que el cambiante ritmo marca el estado de ánimo de la protagonista y la pesadez del ambiente:

En una media noche de enverano dientro el calor y la calladez espesa, desganada, asentada en la cucina con el copo de café, con un pedazo de pan y aceituna.

La luz de la lámpara se alonjaba como una isla consumiendo mis palabras...

"Que no quede piedrida la niña chica en medio del mundo".

¿Qué es lo que quiere?

¿Cucla para jugar?

¡No!

Solamente una calle para caminar.

¡Ma todos están ocupados!

¡Todos están trubiados!

Y ella está tan sola...

No encontra una mano, una mano no encontra. 
El dolor de su soledad la acerca a la reflexión existencialista para analizar
la causa;

[...] Ay veses que so mujer

Que traye la destruxion al destino

Con un amor dulse,

Espinoso,

Desesperado.

Ay veses que so ninia chica

Arasgando subito,

Todas las mascas.

("Me pregunto")

El poema "Existensia" pone de manifiesto su desasosegado vivir, sus frustraciones. Analiza los desordenados deseos insatisfechos de niña, de mujer y de madre, avivándolos hasta llegar a la locura, hasta gemir de dolor,
que oculta bajo una máscara:

Me aserco de mi

Para realizar la existensia

De los deseos en combate.

¡No!

No los areto,

No los enteropo.

Los encorayo con pasion

Asta yegar la locura,

Para sintir la tempesta

Para jimir de dolor...

Ma el pelo

Con su fortalesa fina,

Con su sensia sabia,

Deviene masca

Por cubrir la vida

De una ninja,

Una mujer,

Una madre...

El deseo de fusión con el otro parece inalcanzable en vida. La fusión eterna y espiritual, no sólo física, llegará con la muerte. Sólo ella curará su melancolía, pues el amor sobrevivirái a la muerte:

Cuando la escuridad

Cubrira mi cara 
Yla tuya

$Y$ vamos a flotar en lo vasio

$O$ en los fondos cubiertos

Con montones de tiempo,

Ai, muestro esprito

Va creser en cada letra y sinio,

Va desbrochar como un corriente de fuego,

$V$ a ensender palabras

Piedridas entre las medianas del tiempo...

Entonses, muestros nombres

Se van a grabar en los caminos de seczeto

$Y$ van a abrir las puertas de union.

("En el fondo del tiempo")

El paso del tiempo, que para Matitiahu es destructor (recordemos sus efectos en la añorada Salónica y la desaparición de personas queridas), se convierte ahora en su esperanza, pues el amor es la única fuerza humana capaz de superar la muerte. ¿Existe fatalismo, amargura, resignación? Si tal cosa parecía en el transcurso de sus versos, vemos que en los ültimos poemas del libro se produce un cambio de actitud. La añoranza de paraísos perdidos (de todos, no sólo el del amor) concluye, no con la aceptación del presente, sino con un propósito de cambiarlo mediante la acción. Y comienza por la búsqueda de significado a palabras y voces interiores. Anhela interpretaciones y predicciones que llenen su vacía existencia y mitiguen su dolor, que le traigan palabras y mensajes de los seres que se fueron. Busca una explicación a su estado psíquico desde la parapsicología más que desde la psicología científica:

Enflamada de palabras

Que suben del abismo

Que se plantan en la tierra

$Y$ yevan sinieficasiones

A lo desconosido,

Me vo ande la endevina,

Por entender ruidos de paredes,

Por descubrir muvimientos

Basho tejados transparentes,

Por yevar a mis entranias

La sabiduria de la mente,

Por yenar mis manos vasias,

Y desbrochar dolor 
Cubierta con voses

De otros mundos.

("Enflamada")

Entre tanto dolor, ansía la paz de su espíritu:

[...] La luz garrea como un rayo

a fin de topar un lugar para el reposo

y retornar su meollo robado

y dar abrigo a su alma depierdida.

("La guera de la luz")

"En el camino a Jerusalem", de vuelta a casa tras su viaje a España, observa cómo el sol del invierno potencia los colores: el azul del cielo, el verde de los campos. Todo ese estallido de colores alegres contrasta con la tristeza de sus pensamientos, y se repite que tiene que buscar una solución:

En el camino a Jerusalem

Rayos de sol se encolgaban

En el yelor del envierno.

La vedrura reflectaba en la claridad

Tocando la tristesa de mis ojos,

Basho el sielo blu

Un combate de colores nasia.

Truviada de mis penserios

Via que mis palabras alborotadas

Caian en lo vasio

Tetereando como el eco que desia sin quedar:

"Una sulusion se debe de topar..."

Y se reafirma en su decisión en el último poema de Vela de la luz. En la Plaza de Isaac Rabin, otra vez entra en contraste la luz del sol con su tristeza interior. Pero, mediante la insistente anáfora ("Quería") y el paralelismo sintáctico, parece decidida a renunciar a los nostálgicos halagos del recuerdo y enfrentarse a la realidad esperanzadora:

El sol y el viento rodeaban la plasa

Solombras mudas caminaban yenas de dolor.

El sielo jimía

Los ojos undidos en el miedo.

Un tapet de sebo ensendido

Se espandia basho las pisadas, 


\author{
Calor de figuras \\ $Y$ de candelas tristes \\ Subia como una onda. \\ En el sielo palpitaba el sol. \\ Queria rasgar nubes de ansia, \\ Queria tocar la luz. \\ Que queria vestirse \\ Con alas de esperansa.
}

("En la Plasa de Isaac Rabin")

Una inmensa sed de amor, lato sensu, habita el corazón de la poetisa. La ausencia del objeto del amor la conducen a la añoranza, a la melancolía. Se detecta una búsqueda constante del absoluto amor en una realidad que lo niega. En sus poemas, el sujeto poético, yo, se halla inmerso en la soledad, en el vacio, en la oscuridad. Pero no se aprecia una renuncia, pues se recrea el amor a la vida: se aferra al pasado, con el deseo de recobrar su paraíso perdido. Ésta es su esperanza final.

Utiliza un lenguaje sencillo, elemental, intuitivo, que refleja la realidad espiritual. La soledad adquiere relieve estético. Matitiahu se compenetra con el mundo natural, ya lo hemos dicho, pero impone su conciencia. Juan Ramón Jiménez decía: "Tened siempre presente que a la soledad no se puede ir sino con bagaje suficiente en el alma para colmarla de sentido" 20 . Se adentra entre la multitud para acallar esa soledad de la que está plena. Son poemas de intensión, no de extensión, que consiguen introducir al lector en el mundo interior de la poetisa mediante la selección de un vocabulario real (ni sorprendente ni extraño) en el que los elementos denotativos trasponen la realidad a un plano de belleza y el subjetivismo personal se carga de notas sugeridoras. Así adquiere significado pleno el uso, frecuente en toda su obra, de un léxico connotado: tempestad = dolor, agitación, inquietud, desesperación; máscara = fingimiento, ocultación; oscuridad = noche, muerte, mundo perdido; sol y fuego = amor, pasión, esperanza, felicidad; manos vacías = existencia vacía, desolación, soledad; luz y color = amor, satisfácción, esperanza; hielo e invierno = dolor, tristeza, soledad, añoranza, insatisfacción; espinas = dolor; pájaro = desamparo, inocencia; agua, mar y olas = temor, desconocimiento, esterilidad, desamor; silencio = soledad, angustia, temor. No faltan imágenes antropomórficas: pies, labios, manos, entrañas... Como vemos, todo es plasmación verbal de la idea central de su poesía: la confrontación del tiempo recordado y el tiempo desde el cual recuerda.

"En Libros de prosa (ed. De Francisco Garfias), Madrid (Aguilar) 1969, p.496. 
La creación estética surge de una experiencia que se manifiesta espontáneamente; pero interviene, posteriormente, la voluntad de la poetisa, La büsqueda del símbolo se realiza por la vía de la emoción, no por la de la intelectualización. Movida por un recuerdo emocionado, busca los rasgos esenciales para transmitirlo al lector. Alude a personas, objetos, ciudades y lugares (que a veces son precisos, pero en ocasiones la localización es vaga e imprecisa) que por ser añorados se cargan de belleza, a lo cual contribuye la adjetivación. Todo es breve y discreto en las descripciones, como un apunte que eterniza el momento. Para Matitiahu, que se rnueve entre el presente y el pasado, el tiempo no cuenta. Mas en algún momento se perturba esa intemporalidad (los efectos de la guerra, las ruinas históricas, la muerte). Esa carga real marca la tragedia de su historia, Ia tragedia del paso del tiempo que viene a romper el equilibrio armónico, a perturbar el orden interior de la autora.

La sensibilidad confiere unidad a su obra: es el corazón de la poetisa el que canta. Se detecta una concepción de la poesía como comunicación, y para ello se sirve del verso libre, reposado y penetrante. Es una poesía carente de artificiosidad.

Observamos, finalmente, que el tema judio aparece relacionado con su pasado familiar, con los viajes a la tierra natal de sus antepasados, con los acontecimientos históricos que padecieron los judíos. Y todo ello sin dramatismo. Sólo encontramos trísteza, melancolía, evocación de recuerdos. Sin embargo, se enfrenta con rabia a la realidad política de Israel:

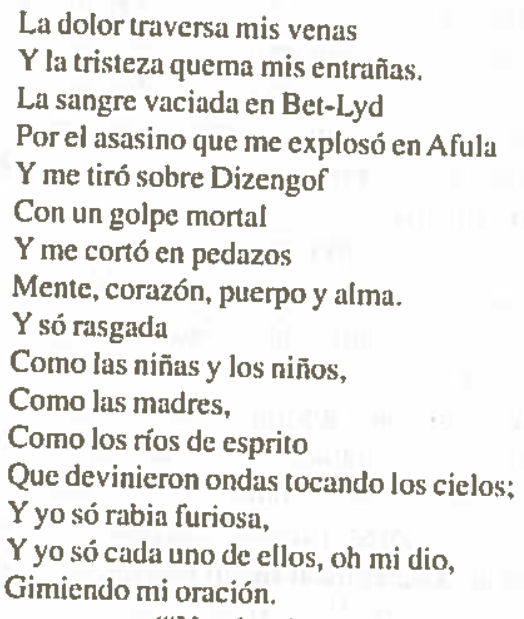

("Yo só cada uno de ellos")

o se angustia por el hijo que está en la guerra, como en el sentido poema "EI
selencio". 


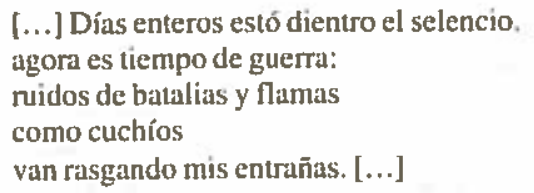

No existe crisis religiosa explícita o implícita, ni siquiera como postura estética. Su concepción de Dios es panteísta: todo es reflejo de la esencia de Dios, al que identifica con las personas y las cosas. Y en ese panteísmo lírico se sume la poesía de Matitiahu.

En "Las palavras" revela su concepción de la poesia:

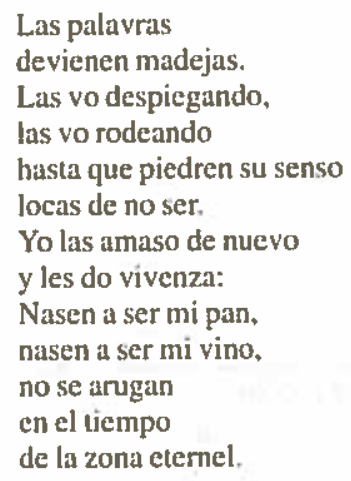

Margalit Matitiahu escribe sobre los sentimientos de una mujer, de una madre, de una niña, y lo hace, como ella misma ha dicho en muchas ocasiones, con la lengua de sus raíces, entonces llamaradas luminosas de un mundo perdido y ahora reencontrado. La experiencia poética en judeoespañol ha sido muy importante para la autora, hasta el punto de que, según nos confesó, cuando últimamente escribía poesía, las palabras en hebreo 'fuyían' de su mente. $Y$ es que Matitiahu se emociona cuando escribe en 'español', al que encuentra más "expresionable" y más suave que el hebreo.

Hemos de destacar, por ültimo, la importancia ${ }^{21}$ de escribir poesía en estos tiempos con una lengua tan inusual como es la sefardí, sobre todo por

${ }^{21}$ Abundando en este aspecto, no podemos dejar de reproducir las palabras de Shmuel REPHAEL, profesor de Estudios Sefardies en la Universidad de Bar-1lín, en el prólogo a Matriz de luz: No hay duda que Matitiahu hace un trabajo innovatorio en el ámbito de la poesía judeo-española. Innovatorio en el sentido que su obra no representa una continuación directa de ninguno de los moldes y estrucluras "clásicas" de esa poesía. No escribe romanzas, ni canciones, ni coplas. Sus poemas no intentan imi- 
lo que supone de loable intento de continuar su uso en la creación lírica actual ${ }^{22}$. Nosotras, con el presente artículo y con próximos estudios, deseamos contribuir a la difusión de esta poesía, convencidas de que la Historia de la Literatura Española debe enriquecerse y completarse con la inclusión de gé-
neros como éste pertenecientes a la moderna literatura sefard? ${ }^{3}$. casi todos los poetas que escriben en judeo-español. Matitiahu trae a sus poemas una quienes crecieron y educaron era conocido, ni quizús entendido, por sus ancestros, a las otras generaciones nutriẻndose de la poesía "clá-

"En A. M" RIAN̂

Judaicos 3 (en prensa).

judeoespañol y la poesía de autor hoy", Estudos

CASQUERO, "Las adaptacios a propósito del gẻnero narrativo en M" C. MARCOS infiemo (Esmirna, 1908)", Enes literarias en un 'romanzo tresladado': El buraco del Netherland, 1999, vol. II, pp. 538-545. 